\title{
HISTÓRIA COMPARADA DO MUNICÍPIO PEDAGÓGICO NO BRASIL E EM PORTUGAL: OS CASOS DE UBERABINHA E MAFRA.
}

\author{
Carlos Henrique de Carvalho ${ }^{1}$ \\ Luciana Beatriz de Oliveira Bar de Carvalho
}

\section{RESUMO}

Como pesquisa pertinente à história da educação em Uberabinha e Mafra, este estudo centrou-se no período da primeira República brasileira. Esse recorte se justifica porque a mudança de regime de governo (monárquico para republicano) ocorreu nos dois países, assim como um debate intenso sobre a expansão do ensino público na esfera municipal; prova disso são os numerosos decretos e as leis relativos à necessidade de se implantar a escola pública nas duas cidades. No caso do Brasil, o marco cronológico inicial é 1888 ano em que Uberabinha se emancipou politicamente de Uberaba — e o final é 1928 ano de publicação dos últimos decretos que criaram a reforma educacional Francisco Campos, em Minas Gerais. No caso de Portugal, o período (1888-1927) começa no fim da monarquia — em parte, porque a República portuguesa só começou em 1910; em parte porque foi quando a expansão do ensino público começou e quando o processo de municipalização iniciado em 1870 avançou. A data-limite é 1927 porque nesse ano o ensino primário passou por uma reforma curricular; em Mafra, ela começou em 26 de outubro de 1928, quando o decreto 16.077 foi publicado em consequiência do relatório da comissão criada para alterar os programas curriculares do ensino primário.

Palavras-chave: Brasil. Portugal. Município Pedagógico. Educação. República.

\section{COMPARATIVE HISTORY OF THE CITY TEACHING IN BRAZIL AND PORTUGAL: THE CASES OF UBERABINHA AND MAFRA.}

\begin{abstract}
As research relevant to the history of education in Uberabinha and Mafra, this study focused on the period of the First Brazilian Republic. This angle is justified since the regime change of government (monarchical to republican) occurred in both countries, as well as an intense debate over the expansion of public education at the municipal level, proven by the numerous decrees and laws relating to the need to deploy public schools in both cities. In Brazil, the initial limit time is 1888 - the year Uberabinha emancipated politically Uberaba - and the end is 1928 - the year of publication of the decrees that created the recent educational reform Francisco Campos, Minas Gerais. In Portugal, the period (1888-1927) begins at the end of the monarchy - in part because the Portuguese Republic only began in 1910, partly because it was when the expansion of public education began and when the process of decentralization started in 1870 advanced. The date is 1927 because that year the primary school curriculum has undergone a makeover, in Mafra, it started in October 26, 1928, when the decree was published in 16077 following the report of the committee established to change the curricula at primary.
\end{abstract}

Keywords: Brazil. Portugal. Municipality Education. Education. Republic. 


\section{INTRODUÇÃO}

Elaboramos este estudo a fim de analisar e discutir o contexto educacional brasileiro e português, conforme as propostas educacionais apresentadas e discutidas na Câmara Municipal de Mafra (Portugal), contrapondo-as e comparando-as com as de Uberabinha (Brasil, Minas Gerais) no intuito de aprofundar as contradições estabelecidas na ambiência educacional luso-brasileira. Logo, este estudo faz uma análise comparativa de duas realidades educacionais, de dois municípios que carregam traços significativos comuns - a mesma língua oficial e experiência histórica semelhante - que Eduardo Lourenço chama de espaço lusófono ${ }^{3}$.

António Nóvoa corrobora essa assertiva ao frisar que o mundo da lusofania ${ }^{4}$ é um território ocupado pela diversidade social, cultural, política e econômica, própria de cada país, e uma dessas realidades - que ele tem procurado construir como objeto de estudo “[...] é essa comunidade imaginada que dá pelo nome imperfeito de lusofonia. Aqui, a possibilidade de um pensamento histórico e comparado torna-se tão evidente que nos espantamos com a ausência de estudos e pesquisas". 5 Nessa via de raciocínio, Justino Magalhães, ao abordar os espaços luso-brasileiros, já no fim do século XIX, salienta que

O século XIX ficara marcado por ciclos comuns de um e de outro lado do Atlântico - uma mesma acção de vulgarização e estruturação da cultura escolar junto dos diversos públicos, através da multiplicação da rede (na base de uma paroquialização) e da articulação entre a gratuidade e a obrigatoriedade; através de uma mesma resposta aos factores de resistência; através de uma mesma estrutura inspectoral. ${ }^{6}$

Optamos pela história comparada na área educacional porque pouca atenção é dada a essa temática entre cientistas da educação ou entre historiadores - prova disso é o baixo número de dissertações e teses sobre o assunto; também porque sentimos necessidade de recuperar a memória do universo educacional brasileiro e português, isto é, das duas cidades citadas há pouco. A prática da comparação na pesquisa no campo da educação tem sido comum e tem produzido resultados úteis para se compreenderem realidades distintas entre si, para se fazer olhar ir além de espaços específicos e para se entender a formação de diferentes situações educacionais.

Mesmo que seja "[...] a base de quase todas as formas de pesquisa", ${ }^{7}$ a comparação exigiu cautela. As categorias de análise envolvem espaços específicos no nível local e global, difusão ideológica da centralidade da educação no desenvolvimento do progresso social e questões próprias de cada localidade, ou seja, dos municípios, tais como discussões sobre financiamento do ensino público, organização curricular, estrutura administrativa das escolas e outras. Dito de outro modo, era preciso estabelecer categorias de análise que nos permitissem aproximar ou distanciar as realidades estudadas e compreender como os dois espaços - o português e o brasileiro - definiram sua trajetória ao longo do tempo, marcados por certas características comuns: condições desfavoráveis à instrução e a presença marcante de um contingente enorme de analfabetos no período estudado.

Compreender essas duas localidades separadas pelo oceano Atlântico exigiu conhecer bem os princípios teórico-metodológicos da história comparada. Isso porque, diria António Gomes Ferreira,

[...] a comparação está, diríamos, omnipresente em educação, pois, sempre que procuramos compreender onde nos inserimos recorremos a outros contextos onde se desenvolvem realidades parecidas. A comparação é seguramente uma forma de alcançar um novo saber e a Educação Comparada quer que este se construa 
sobre factos que pertencem à realidade educativa de modo a dar a esta uma compreensibilidade que a simples análise num só contexto não permite. ${ }^{8}$

Com esse horizonte teórico-metodológico em mente, o historiador deve saber que, para ser fiel ao seu ofício, se resguardar de conclusões ou julgamentos a priori, seus questionamentos ao passado são determinados e condicionados pela sua inserção no presente e que suas abordagens sempre estarão sujeitas a revisões; por isso não se alcança a suposta objetividade em estudos concebidos como definitivos, mas sim quando se está convicto da necessidade de rever procedimentos e concepções. Só assim, ancorado nesses princípios, ele terá condições de compreender e explicar situações e problemas investigados, mesmo que estejam localizados em espaços e temporalidades distantes de onde o historiador desenvolve seu ofício.

Assim, com um olhar amparado pelas precauções teórico-metodológicas da história comparada, buscamos cobrir um conjunto de questões, e não simplesmente nos debruçarmos sobre o problema educacional dos dois municípios em estudo. Quisemos abranger várias categorias de modo a permitir uma compreensão ampla dos processos formativos da organização do ensino nos municípios brasileiros e portugueses, representados por Uberabinha e Mafra. Com tais cuidados metodológicos, balizamos o recorte temporal em razão da relativa autonomia e descentralização observadas num e noutro país. No caso brasileiro, elas advieram da forma republicana de governo, que pôs em pauta o tema da instrução pública, que, com os ideais de democracia, progresso e ordem, norteou a apresentação de propostas para a instrução em cada município. A instrução passou a ser vista pelas elites governamentais locais como uma via para se ascender ao Estado democrático/moderno, daí o movimento expressivo pró-instrução pública em geral. No caso português, as medidas descentralizadoras e o fomento do municipalismo começaram no regime monárquico e foram reforçadas pela primeira República, implantada em 5 de outubro de 1910.

$\mathrm{Na}$ delimitação do objeto de estudo, tentamos não cair em armadilhas. Por exemplo, determiná-lo conforme a história cronológica ou enquadrá-lo nos marcos da história política. Nesse caleidoscópio onde tudo parece ser permitido, vemos a educação como fenômeno histórico passível de ser investigado à luz da própria história. Partimos, então, do pressuposto de que o fenômeno educacional se liga à produção e reprodução da sociedade humana, pois os homens, ao produzirem sua vida material, produzem também um conjunto de idéias e representações diretamente entrelaçadas com sua atividade material.

A relevância deste artigo para a sociedade uberabinhense e mafrense está na demanda social pela redescoberta do passado. Nas pesquisas que fizemos, não encontramos muitos trabalhos na área da história comparada sobre esses dois municípios. Estamos cientes de que se trata de uma tarefa difícil; mas a vemos como necessária. Há várias formas de se pensar na história em condições particulares e específicas, com suas atividades múltiplas - política, econômica, social, cultural, religiosa e literária - que compõem o espaço onde homens e mulheres vivem situações sociais reais, com necessidades e interesses distintos. Assim:

Imaginamos que a história é a experiência humana e que esta experiência, por ser contraditória, não tem um sentido único, homogêneo, linear, nem um único significado. Desta forma, fazer história como conhecimento e como vivência é recuperar a ação dos diferentes grupos que nela atuam, procurando entender por que o processo tomou um dado rumo e não 
outro; significa resgatar as injunções que permitiram a concretização de uma possibilidade e não de outras. ${ }^{9}$

Como as possibilidades de investigação empírica são grandes, recortamos as fontes; mas incluímos, com frequência, outros achados de interesse de uso e preservação da memória educacional. Ao selecionarmos os documentos que integraram este estudo, ficamos atentos às obscuridades nos rastros empoeirados de livros e papéis velhos e esquecidos e às possíveis armadilhas que as intempéries e uso incorreto dos registros oficiais podem armar para se escrever a história. Assim, o corpus documental em que este trabalho está centrado resulta de um levantamento e registro das fontes nos arquivos de Mafra, na Torre do Tombo e na Biblioteca Nacional de Lisboa. No município de Uberabinha, buscamos fontes no arquivo público e na Câmara Municipal, onde transcrevemos todas as atas das reuniões dos vereadores de 1892 a 1928. Os documentos pesquisados apresentam uma riqueza profunda de informações e dados numéricos que salienta a importância de compreendermos a relevância da instrução pública nesses dois municípios.

\section{AÇÕES EDUCACIONAIS EM UBERABINHA E MAFRA: O LUGAR DO MUNICÍPIO}

O analfabetismo foi visto como fator gerador de problemas econômicos e sociais no Brasil e em Portugal no fim de século XIX e no começo do século XX. Inversamente, a educação escolar foi vista como fator central para que esses países progredissem e se modernizassem. Alvo do descaso da monarquia de cá e de lá, a educação do povo, ou a extinção do analfabetismo, esteve na pauta dos agentes políticos da primeira República brasileira e dos republicanos de Portugal (embora lá a República tenha sido instaurada algumas décadas após a monarquia dar lugar ao republicanismo aqui). A autonomia relativa e os princípios de descentralização advindos do governo republicano puseram em pauta a instrução pública, que ganhou importância, pelo menos discursivamente, na estruturação política, econômica, social e cultural de ambos os países. Ela se alinhava aos ideais de democracia, progresso e ordem - princípios do liberalismo. Passou a ser vista pela elite governamental como via de ascensão social e sustentação do chamado Estado democrático de direito. Por isso, mas não só, verifica-se um movimento expressivo próeducação pública no Brasil e em Portugal.

A República brasileira resultou da aliança entre Exército, fazendeiros do café ligados ao capital internacional e setores da camada média; e sua proclamação foi facilitada indiretamente pelo desprestígio do regime imperial, pela abolição da escravatura e pelo enfraquecimento momentâneo das oligarquias ditas tradicionais. ${ }^{10} \mathrm{O}$ novo regime se ergueu com um aparato legal fundado no modelo liberal dos Estados Unidos e no positivismo, em voga no século XIX; noutras palavras, aqui, o moderno se identificava com princípios liberais e positivistas então divulgados na Europa e na América do Norte. Imbuídos dessas concepções, os republicanos apresentaram propostas para mudar o quadro desfavorável da educação e criar condições para o desenvolvimento econômico e político do país, isto é, para fazê-lo alçar ao panteão das nações tidas como mais civilizadas. Eis a linha discursiva do debate sobre os problemas educacionais nas discussões parlamentares 
na capital federal de então (Rio de Janeiro), nas assembléias legislativas estaduais e nas câmaras municipais de muitas cidades.

Após a proclamação da República portuguesa, os responsáveis pelo novo regime de governo buscaram reformar o modelo educativo vigente em todos os níveis de ensino mas deram atenção especial ao analfabetismo. Os reformistas separaram o conceito de instrução do de educação; entendiam que, para chegar a esta, aquela era condição essencial. Pretendiam não só instruir, mas também educar, ou seja, enaltecer os valores e princípios cívicos da pátria lusitana, seus feitos coloniais e seus heróis etc. Pela instrução cívica, iniciada na infância, o país recuperaria sua condição natural de potência européia. Também promoveram a laicização do ensino para retirar da igreja católica boa parte de seu controle sobre a educação. Assim, para os dirigentes da educação do período republicano, esta entraria numa fase áurea, pois até a proclamação da República portuguesa (5 de outubro de 1910) não se pensava muito na educação básica nem se cogitava a criação do Ministério da Instrução Pública de imediato (foi criado em 7 de julho de 1913, pelo decreto-lei 12). Quanto ao regulamento para o ensino primário, as medidas iniciais foram tomadas em 22 de julho de 1911 e visavam corrigir a condição de abandono a que monarquia relegou essa modalidade de ensino. Os republicanos lusos levantam, então, duas bandeiras: instrução pública para instruir e para educar.

Os republicanos viram - e consideraram - a educação como fator de eficácia. Isso implicava uma dinâmica congruente entre diversas forças locais, orientadas para um projeto autônomo (incluindo disciplinas adaptadas aos locais), e a confluência dessas dinâmicas num ideário nacional (o patriótico e o municipal compunham a mesma cidadania: a do progresso e da modernização). Nesse sentido, buscamos identificar o ideário que embasava a República em seu começo, o papel esperado da educação nesse ideário e como ele repercutiria na esfera municipal. Como era o Estado que se via como liberal, seja o estado português ou o brasileiro, à educação se reservava um espaço fundamental, tendo em vista tanto as experiências de desenvolvimento no século XIX que abriram caminho à industrialização e ao progresso europeus, ao menos em países já industrializados, quanto a necessidade de se formar o cidadão, seja para a prática política, o exercício da cidadania, a preservação da tradição humanista ou a formação profissional.

Fosse contrária ou favorável a posição da maior intervenção do Estado na sociedade, pode-se dizer que a crença no poder da educação como formadora da consciência do país, de preparação para a democracia e para o progresso material era disseminada entre as elites; e a República apareceria como sistema político apto a oferecer as luzes ao povo, sobretudo pela educação, com seu poder civilizatório. Esta passou a ser tida como direito do cidadão, e aí se assentaram os debates sobre educação municipal como forma de o local promover e propiciar a todos o acesso a essa condição essencial ao exercício da cidadania. Pensada e construída com iniciativas dos municípios, a escola se configurou como estrutura-base para se garantir localmente os princípios universais da cidadania. Logo, “[...] como se trata de um direito, é preciso que ele seja garantido e para isto a primeira garantia é que esteja inscrito em lei de caráter nacional", ${ }^{11}$ mas estendida ao local. Este, por sua vez, passou a tomar medidas para consolidar sua aplicabilidade aos munícipes.

Nessa lógica, o período 1888-1928 pode ser caracterizado em Uberabinha e Mafra. A cidade mineira chega à condição de município em 1888, marco inicial da pesquisa, cujo marco final é 1928, quando o governo de Minas Gerais fez reformas significativas na educação no estado - por exemplo, disponibilizou mais verbas para a rede de ensino estadual e criou escolas em muitos municípios, dentre os quais Uberabinha. De 1888 a 1910, Mafra ainda estava sob o regime monárquico, mas os municípios 
portugueses tinham certa autonomia no plano político (ao menos mais que no Brasil) no período monárquico, sobretudo nos últimos anos do século XIX e nos primeiros do século XX, quando se observa uma relativa descentralização administrativa: a organização da instrução pública local cabia às câmaras municipais. Como marco final, escolhemos 1928 porque em 26 de outubro desse ano o decreto 16.077 alterou os objetivos do então ensino primário, com a publicação do relatório de uma comissão constituída para modificar os respectivos programas curriculares do ensino primário.

Embora essa contextualização política sugira semelhança entre os dois municípios, eles se diferiam, especialmente porque são espaços culturais, políticos e econômicos distintos, o que lhes dá dinâmicas distintas. Um ponto que os distingue é que Uberabinha investia na educação de crianças pobres, doando uniformes e material escolar. Em Mafra não havia essa preocupação com os menos favorecidos; vários textos de jornais tinham relatos de pais dizendo que os filhos não frequentavam a escola porque não tinham roupas - mas alunos pobres com mais potencial intelectual eram cooptados com frequência, pelo menos no período monárquico; iam ser professores, médicos, advogados... De fato, jornais, atas e legislação educacional sugeriam um movimento pró-descentralização no concelho de Mafra, que buscou instruir seu povo sem se preocupar com legislação nacional em vários momentos. Contudo, não percebemos em Uberabinha leis municipais relativas à descentralização educacional; talvez porque, no Brasil, não se falava então em descentralizar o ensino, assim como não se cogitava que a legislação brasileira desse mais poder aos municípios, como o fazia a legislação lusitana.

Desse contexto, merecem destaque as discussões e reformas relativas ao ensino público de nível primário levadas adiante pelos municípios em questão, tendo em vista a pretendida organização e fiscalização desse grau de ensino. Na tentativa de identificar imbricações, particularidades, nexos e contradições, pudemos ver algumas ações em Uberabinha e Mafra. Por exemplo, o balancete da Câmara Municipal de Uberabinha referente à receita do município e às despesas com instrução entre 1919 e 1930 dá uma visão mais ampla do valor anual arrecadado e possibilita compreender com maior clareza a preocupação com a instrução no município. ${ }^{12}$ Os dados revelam um gasto médio anual de 3,5\% com instrução e que o orçamento estimado para a educação quase dobrou em uma década: em 1919, previa-se um percentual gasto de 3,49\% da receita, mas foram gastos $2,38 \%$. Nos anos de 1924, 1925 e 1926, os percentuais gastos superaram as estimativas: respectivamente, os $3,45 \%$, os $5 \%$ e os $9,09 \%$; os gastos foram de $3,60 \%, 8,16 \%$ e $10,06 \%$. $\mathrm{O}$ aumento de verbas se vincula ao empenho do poder municipal em implantar ações para cumprir a lei 278, de 07 de março de 1923, que previa ampliação no número de escolas no município. Essa inquietação do poder público local resultou da intenção de fazer a cidade se desenvolver e progredir, e para isso a instrução era um de seus instrumentos mais importantes e eficazes.

As atas da Câmara Municipal de Uberabinha detalham bem os investimentos. No caso de Mafra, as atas da Câmara não detalhavam, mas sugerem - assim como textos de jornais - que o investimento em instrução primária era demasiado. Assim, os dois municípios investiram muito no setor educacional. Sobretudo por ser essencialmente republicana, Uberabinha já apresentava e aprovava, via Câmara Municipal, leis sobre a instrução pública no município logo nos primeiros anos da República brasileira; enquanto Mafra se preocupava com problemas de instrução pública no município desde o período monárquico, fazendo propostas de construção e melhoria de escolas sob a jurisdição de seu concelho - mas a ação legal voltada à instrução ocorreu só no século XX, após a instauração da República portuguesa. Essas diferenças, porém, não impedem comparações entre eles - se forem realizadas transversalmente, ou seja, com base em imbricações, 
particularidades, nexos e contradições - nem anulam a semelhança entre as duas cidades relativamente a terem uma preocupação em comum: a educação, então sob responsabilidade do município. Compará-los nesse caso não é analisá-los de forma estanque, mas de modo a buscar a tecedura da teia existente e as desconexões presentes nos dois lados do oceano Atlântico.

E essa preocupação nos dois municípios - e as ações dela derivadas caracterizam o que alguns pesquisadores categorizam como "município pedagógico". 13 Assumir como tese a existência de município pedagógico supõe, além de aspectos identitários e de transformação, que a cidadania embasou a sociabilidade educativa; ou seja, que o município criou condições mínimas para se constituir uma "pedagogia escolar", que se tornou uma amálgama social importante, dada a realidade da época nos municípios em estudo. Se não se pode dizer que tal pedagogia fora assumida plenamente por quem respondia pela direção política do município, também não se pode afirmar que não fora vivida pelos educandos como destino de vida, contrastante ou não com os cidadãos de outros territórios.

O município pedagógico surge, então, como complexo estrutural (singular) e instância autônoma. Há documentação histórica que informa e consagra o desenvolvimento do município, assim como há aquela que legitima a descentralização e autonomização e aquela relativa aos projetos e às realizações municipais. Nelas, o município é objeto histórico: teve vida própria - comprova-o o manancial de documentos específicos; é possível articulá-lo com a política nacional/global sem se perder de vista o local, ou seja, sua identidade, pois nele se identificam coletivos e agentes que transformaram a vida municipal num projeto de características próprias, experiências e vivências distintas daquelas observadas no quadro mais geral do nacional.

\section{CONSIDERAÇÕES FINAIS.}

Ao recuperar as singularidades educacionais privilegiando não mais os aspectos macroestruturais, e sim as características regionais e locais, além de tatear outra realidade educacional: o município português de Mafra entre o fim do século XIX e o início do XX. A pesquisa em Mafra exemplificou umas das dificuldades metodológicas do trabalho no campo historiográfico: a documentação vasta, que suscitava muitas possibilidades, isto é, embaralhava os caminhos. Mas, no decorrer da pesquisa, centralizamos esforços numa documentação mais específica, buscando aproximá-la da que foi trabalhada no Brasil.

Em sua análise da complexidade do estudo de dimensões locais com suas interrelações com o nacional, Carlo Cipolla aponta algumas dificuldades ao se considerar só um aspecto dessa inter-relação, pois "[...] o grau de instrução de qualquer sociedade, seja nacional ou regional, é o resultado de um complexo de fatores inter-relacionados. De fato, a instrução é apenas um aspecto de uma realidade sócio-cultural". ${ }^{14}$ Nesse sentido, uma das dificuldades que enfrentamos foi estabelecer a relação entre local e global. Há muito a historiografia considera que as realidades criadas pelas experiências da atividade humana não podem ser analisadas só numa perspectiva globalizantes, mas também segundo suas singularidades, que se manifestam, sobretudo e de forma riquíssima, no nível local. Generalizada pela corrente historiográfica dos Annales, essa postura possibilitou, além da abertura de fronteiras interpretativas e da ampliação do campo das fontes documentais, estabelecer novos horizontes para as investigações, tais como a análise da realidade local sem perder de vista o todo da sociedade.

Assim, pensar no nascimento e na consolidação da história da educação como outro domínio da história é inseri-la e compreendê-la como resultado de um interesse maior dos historiadores nas imbricações da sociedade contemporânea e nos problemas educacionais, ao 
procurarem identificar e situar os impactos dos fenômenos educativos nas várias instâncias das formações sociais. Essa constatação nos possibilitou (re)pensar nos paradigmas explicativos do pensamento historiográfico ligado à educação já no fim do século XIX, em especial apos a constituição dos grandes sistemas nacionais de ensino na Europa, de características liberais e que incorporaram à pedagogia os avanços científicos. ${ }^{15}$ Esses paradigmas ganharam novo impulso na década de 1920, com a escola dos Annales, que constituiu então o ponto central de renovação historiográfica para décadas posteriores, abrindo caminho à História Nova, que parte de outra perspectiva do "fazer a história": interessam agora à narrativa histórica não os "grandes homens", os "grandes acontecimentos" ou as "grandes sínteses", mas os pais, as crianças, os professores, as escolas - numa palavra, um universo pouco explorado pela chamada "historiografia tradicional".

É na esteira dessas concepções historiográficas que afloraram novas interpretações dos fenômenos históricos, em particular daqueles relacionados com as formas educativas, exigindo que se acompanhassem sua formação, seu desenvolvimento e suas interrelações/implicações com o Estado, a sociedade e as instâncias municipais. Noutros termos, buscam-se formas distintas de abordagem dos fenômenos educativos: sejam legais (reformas e leis educacionais), pedagógicos (métodos de ensino e práticas educativas), didáticos (manuais, revistas e impressos escolares em geral), instituições (arquitetura e cultura escolar) para se compreender a história da educação segundo uma reflexão que a conceba como domínio científico com referência à história e à educação. Essa "dupla genética" permite encetar interpretações sobre os movimentos contemporâneos históricoeducacionais, desenvolvidos sob forma de revolução, reforma ou resistência e constituídos por princípios inseparáveis das circunstâncias históricas.

$\mathrm{Na}$ trajetória dessa renovação historiográfica, pensar no "fazer da história" é antes de tudo olhar para o ofício do historiador: como este desenvolve seu trabalho nesse campo científico, como lida com "leis" da história e as "transforma" em ciência com base em fatos e personagens históricos (econômicos, políticos, sociais, educacionais, culturais etc.) sem cair nas "armadilhas" de "produzir" narrativas generalizantes de acontecimentos do passado (próximo ou remoto). ${ }^{16}$ Ao explicitar a conexão entre conhecimento histórico e literatura, Paul Veyne problematiza a história vista como ciência pura e objetiva; segundo ele, história e narrativa literária têm muito em comum, pois os recursos que o historiador dispõe não diferem muito daqueles disponíveis ao novelista: ambos se apropriam de personagens e eventos (factuais ou não) e os ordena e significa para envolver o leitor num mundo a que este não acede a não ser pela linguagem empregada por quem narra.

Pressupomos que o fenômeno educacional se vincula à produção e reprodução da sociedade humana, qual seja: as idéias e representações que se entrelaçam diretamente com a atividade material dos homens ao produzirem sua vida. Assim, a realização deste estudo exigiu discutir com mais profundidade a noção de município pedagógico, visto como lugar e instância histórico-pedagógica. Por definição, local pedagógico é o contexto, é uma entidade geográfica e sociopolítica. A indeterminação do global e a transformação histórica do nacional configuram o local como instância da realização educativa, escolar, pedagógica, política (social e cultural); mas têm suas características. Ora, embora haja determinantes nacionais - políticos, econômicos, sociais ou culturais —, o município é capaz de criar condições específicas para sua organização sociopolítica. Os parâmetros definidores do local são o lugar (topos/território), o contexto, a agência (poder/protagonistas), os sujeitos/beneficiários, a finalidade, o projeto/investimento, por fim, o significado da ação histórica. A coerência na organização e na evolução desses parâmetros, configurando um todo harmonioso, singulariza o local. 
O recurso a uma escala temporal e geograficamente pequena pode configurar - e ao mesmo tempo justificar — uma microanálise, mas não como dimensão a priori, que pode estabelecer uma (pré-) definição do local como objeto historiográfico. O critério fundamental de definição historiográfica do local é a autonomia: capacidade de projeção e de decisão. A combinatória da complexidade (singularidade) com a autonomia assegura a identidade. Assim, analisar a história local permitiu redimensionar o antagonismo aparente entre centro e periferia, isto é, local e global, ao deslocarmos a centralidade do problema da discussão para a apropriação de informações sobre as relações que plasmaram os grupos sociais, sobretudo aquelas materializadas nas iniciativas ligadas ao campo educacional em Uberabinha e nas ações desenvolvidas pelas câmaras municipais desse município e de Mafra.

Dito isso, teríamos condições de trabalhar com segurança a história da educação nacional sem ter de conhecer essa história em outras regiões diversas. Afinal, não se pode fazer um estudo da realidade local desvinculado de uma interpretação de tom geral, mais abrangente. Logo, pudemos aquilatar a extensão das propostas teóricas e fazer as correções necessárias, quando se fizeram necessárias. Não fizemos história da educação regional, mas história da educação focada no local, pois recorremos a documentos específicos (textos da imprensa, atas das câmaras municipais, decretos do Poder Executivo e outros) úteis à compreensão da realidade luso-brasileira, isto é, de Mafra e Uberabinha, onde a descentralização não consolidou sua "função" de município pedagógico integralmente; o que distinguiu o municipalismo monárquico (Mafra) do municipalismo republicano (Uberabinha) foi o grau de interação em contexto local.

Nessa lógica, temos de projetar a educação num quadro mais amplo. E essa via deixa entrever a importância de novos ângulos de análise para se compreender a história da educação. Isso implica, por exemplo, um diálogo mais amplo entre nacional e local, tendo em vista promover e estabelecer nexos articuladores entre o geral e particular, nos espaços de interseção ou fora deles. Dito isso, cremos que, com este estudo, ampliamos o conhecimento sobre o processo educativo/instrucional do Brasil e de Portugal no fim do século XIX e nas primeiras décadas do século XX. Rediscutir a centralização e descentralização da administração do ensino público e suas conseqüências para a educação nesses países permitiu compreender a resposta das unidades municipais às necessidades de instrução da população frente à omissão estatal.

\section{REFERÊNCIAS}

BRAY, Mark; THOMAS, R. Murray. Níveis de comparação em estudos educacionais: diversidade de percepções a partir de diferentes literaturas e o valor das análises em multiníveis. Contemporaneidade e Educação, v. 7, p. 127, $1^{\text { }}$ sem. 2000.

CIPOLlA, Carlo M. Instrução e desenvolvimento no Ocidente. Lisboa: Ulisseia, 1969.

CURY, Carlos Roberto Jamil. Legislação educacional brasileira. Rio de Janeiro: DP\&A, 2000 .

FERreira, António Gomes. Percurso da educação comparada: evolução e construção de identidade. Revista Portuguesa de Pedagogia, n. XXXIII, v. 1, 1999.

LOUREnÇO, Eduardo. A nau de Ícaro seguido de imagem e miragem da lusofonia. Lisboa: Gradiva, 1999. 
Magalhães, Justino Pereira de. Tecendo nexos: história das instituições educativas. Bragança Paulista: ed. Universitária São Francisco, 2004.

NÓvoA, António. Tempos da escola no espaço Portugal-Brasil-Moçambique: dez digressões sobre um programa de investigação. In: NÓVOA, António; SCHRIEWER, Jürgen (Ed.). A difusão mundial da escola: alunos-professores-currículo-pedagogia. Lisboa: Educa, 2000.

VIEIRA, Flávio César Freitas. Movimentos Educacionais em Uberabinha: Entusiasmo pela Educação e Otimismo Pedagógico (1919 a 1930). SEMINÁRIO NACIONAL DE ESTUdOS E PESQUISAS HISTÓRIA, SOCIEDADE E EDUCAÇÃO NO BRASIL, 5., 2001, Campinas. Anais... Campinas: FE-UNICAMP, 2001, CD-ROM.

VIEIRA, Maria do Pilar de Araújo. A pesquisa em História. São Paulo, Ática, 1995.

\section{Notas}

${ }^{1}$ Doutor em História pela Universidade de São Paulo (USP). Professor da Faculdade de Educação e do Programa de Pós-Graduação em Educação da Universidade Federal de Uberlândia (UFU). e-mail carloshcarvalho06@yahoo.com.br

2 Doutora em Educação pela Universidade Estadual de Campinas (UNICAMP) Professora da Faculdade Católica de Uberlândia. E-mail lucianabeatrizcarvalho@yahoo.com.br

${ }^{3}$ LOUREnÇO, Eduardo. A nau de Ícaro seguido de imagem e miragem da lusofonia. Lisboa: Gradiva, 1999, p. 112.

${ }^{4}$ LUSOFONIA: s. f (1) "Qualidade de ser português, de falar português; o que é próprio da língua e cultura portuguesa. (2). Comunidade formada pelos países e povos que têm o português como língua materna ou oficial (3). Difusão da língua portuguesa no mundo". Dicionário da academia de ciências de Lisboa. Lisboa: Presença, 2001, p. 310. Como qualquer narrativa do presente, o discurso sobre a lusofonia está historicamente associado a vários momentos de exceção, de que se exprimem coletivamente em movimentos de exaltação, de exacerbação da identidade, aqueles relativos às datas nacionais, aos heróis ou mesmos aos aspectos estilísticos da língua; em última instância, é a busca da afirmação da nacionalidade. É nesse sentido que Eric Hobsbawm salienta a necessidade de se estudarem tais práticas como "invenção da tradição" a propósito da relação de intermediação que se estabelece entre representação e apropriação de símbolos nacionais e, sobretudo, das narrativas históricas.

${ }^{5}$ NóvoA, António. Tempos da escola no espaço Portugal-Brasil-Moçambique: dez digressões sobre um programa de investigação. In: NÓVOA, António; SCHRIEWER, Jürgen (Ed.). A difusão mundial da escola: alunos-professores-currículo-pedagogia. Lisboa: Educa, 2000, p. 127.

${ }^{6}$ Magalhães, Justino Pereira de. Tecendo nexos: história das instituições educativas. Bragança Paulista: ed. Universitária São Francisco, 2004, 41.

${ }^{7}$ BRAY, Mark; THOMAS, R. Murray. Níveis de comparação em estudos educacionais: diversidade de percepções a partir de diferentes literaturas e o valor das análises em multiníveis. Contemporaneidade e Educação, v. 7, p. 127, $1^{\circ}$ sem. 2000.

8 FERREIRA, António Gomes. Percurso da educação comparada: evolução e construção de identidade. Revista Portuguesa de Pedagogia, n. XXXIII, v. 1, p. 124, 1999.

${ }^{9}$ VIEIRA, Maria do Pilar de Araújo. A pesquisa em História. São Paulo, Ática, 1995, p. 11.

${ }^{10}$ COSTA, 1977, p. 16. Segundo essa autora, tais mudanças foram "[...] o resultado desse processo de desenvolvimento e perpetuação de valores tradicionais, elitistas, antidemocráticos e autoritários, bem como a sobrevivência de estruturas de mando que implicam na marginalização de amplos setores da população".

${ }^{11}$ CURY, Carlos Roberto Jamil. Legislação educacional brasileira. Rio de Janeiro: DP\&A, 2000, p. 8.

${ }^{12}$ Cf. VIEIRA, Flávio César Freitas. Movimentos Educacionais em Uberabinha: Entusiasmo pela Educação e Otimismo Pedagógico (1919 a 1930). SEMINÁRIO NACIONAL DE ESTUDOS E PESQUISAS HISTÓRIA, Sociedade e eduCAÇÃo no Brasil, 5., 2001, Campinas. Anais... Campinas: Fe-UniCAMP, 2001, CDROM.

${ }^{13}$ Para Wenceslau Gonçalves Neto pode-ser definir assim a ação, ou a preocupação, das câmaras municipais ligada à questão educacional, pois "O município pedagógico é a entidade administrativa local na Qual as 
autoridades constituídas, avançando para além das dimensões político-administrativas, promovem a educação a uma posição de centralidade para o alcance do desenvolvimento sócio-econômico e para a legitimação do poder. Trata-se de uma categoria ainda em formação, dado seu uso recente, e tem sido identificada no Brasil na segunda metade do século XIX, possibilitada pela existência de uma legislação descentralizadora da gestão do ensino e a extensão da responsabilidade para com a instrução primária aos limites municipais, levando à regulamentação e implementação locais dessa obrigação. Também inclui-se nesse conceito a apropriação que as elites fazem dessa responsabilização, tirando proveito para a concretização de objetivos particulares, relacionados à manutenção da ordem, disseminação de ideologia e delimitação de uma identidade municipal. Deve-se acrescentar que esse movimento é impulsionado, na época, pela crença no poder regenerador da educação e da necessidade de implantação de sistemas escolares para sua implementação”. HISTEDBR. Município pedagógico. Disponível em: www.histedbr.fae.unicamp.br/navegando/glossario/verb_c_municipio_pedagogico.htm. Acesso em: 20 ago 2008. Cabe ressaltar que a categoria município pedagógico foi derivou das pesquisas e análises do professor Justino Pereira de Magalhães, da Universidade Lisboa.

${ }^{14}$ CIPOLla, Carlo M. Instrução e desenvolvimento no Ocidente. Lisboa: Ulisseia, 1969, p. 20.

15 Cf. GASPARD, Pierre. L'histoire de l'education en France. Paris: Pirren, 1984; PROST, Antoine, Histoire générale de l'enseignement et de l'éducation en France, Depuis 1930. Paris: Perrin, 2004.

${ }^{16}$ Sobre a tradição historiográfica francesa, com suas várias gerações de historiadores e múltiplas abordagens depois de 1929, quando foi fundada a Revista Annales, cf.: BLOCH, Marc. Introdução à história. Lisboa: Publicações Europa-América, 1997; CHARTIER, Roger. À beira da falésia: a história entre certezas e inquietude. Porto Alegre: editora da Ufrgs, 2002; Boutier, Jean; JUlia, Dominique. (Org.). Passados recompostos: campos e canteiros da história. Rio de Janeiro: editora da UFRJ/FGV, 1998; BRAUDEL, Fernand. Escritos sobre a história. São Paulo: Perspectiva, 1992; FEBVRE, Lucien. Combates pela história. Lisboa: Presença, 1989; e LE GOFF, Jacques (Org.). A história nova. São Paulo: Martins Fontes, 1990.

Artigo recebido em: 05/11/2010

Aprovado em: $\quad 10 / 12 / 2010$ 